\title{
PLAN FOR CITY IDENTITY ESTABLISHMENT AND CITY MARKETING THE CASE OF KIMPO CITY
}

\author{
Kim Inn \\ Department of Geography, Seoul National University, \\ Seul I5I - 170, Korea \\ e-mail: kiminn@snu.ac.kr
}

\begin{abstract}
The purpose of this study is to provide theoretical methods and practical strategies of creating city identity, and to utilize them as basic tools of city management. Place marketing consists of two parts, place assets making and place promotion. Place asset making is the process of making the place-specific advantage or attractiveness and the place promotion is the process that makes notice of it. The place marketing debates and strategies is quite often confined to partial place marketing, the search for the tactical method of place promotion. However, this study examines the characteristics of full place marketing focused on the place making such as the background, concept, category, participants and principles of place making. This study finds out that the originality, specificity, and indispensability of place asset is the source of competitive advantage. The principles of place asset making are participation, learning and experience, and leadership and networks among actors. The policy implication of this study is that it is most important for the success of place marketing to make competitive assets and eventual city identity.
\end{abstract}

Key words: place asset making, place marketing, city identity, city management

\section{INTRODUCTION: STUDY OBJECTIVE}

Place(City) marketing is aimed at a series of different objectives such as raising the competitive position of the city, attracting inward investment, improving its images and establishing city identity. These objectives are very useful as place marketing tool. And they are interrelated and integrated in doing place promotion and place market. Debates and strategies for the place marketing are quite often confined to partial place marketing, research for the tactical method of place promotion under a limited objective goal. However, this study examines the characteristics of full place marketing focused on place production such as background, concept, place audit, place asset making, and principles of place marketing. 
The purpose of this study has two folds: one is to provide a theoretical framework and method of city marketing procedure in the planning concerns. The other one is to utilize them as basic tools for city management and development. For this, a case study will be made for Kimpo city in a joint concern of city planing and city marketing. Before doing an empirical study of Kimpo, it will be very useful to consider how marketing ideas can be of great relevance to urban management and development.

\section{THE STUDY METHOD}

\section{Some operational definitions of major key words related to this study}

City(place) marketing: the practice of selling places entails public and private agencies who strive to "sell" the image of a particular geographically-defined "place", usually a town or city, so as to make it attractive to economic enterprises, to tourists and even to inhabitants of that place ( Kearn and Philo, 1993 ).

Place asset and place promotion: place marketing consists of two parts, place asset making and place promotion. Place asset making is a process which makes the place specifically advantageous or attractive and the place promotion is an effort to promote the placespecific advantage and its attractiveness.

Place identity: the term "identity" means something refers to a persistent sameness and unity so that a differentiation from others is entailed. City identity can be technically defined as an effort to seek persistent things in the urban mutation and to bring them up as a permanent asset.

\section{Study argument}

This study starts with a viewpoint that most problematic urban issues, whatever they are in geographically defined area, influence deeply on the city image in negative way. The bad images in result of the current urban problem issues critically link to the living conditions of the city, and when the bad images are rumored outside the city they become escalated, and once people become conscious the bad image it will let the city spiral down in many aspects, for example, attraction, competition, investment, etc. To overcome this kind of problem it is necessary to build place asset in the problem area in order to turn out the city's negative image out to a positive one and prevent city conditions from spiraling down.

The city image or identity is usually created on the base of various sources: history, culture, custom, industry, landscape, environment, etc. However, city marketing in reconstructing the image of the city has been limited to place promotion by simply advertising only for the given resources. This study strongly suggests place asset making in the problem areas to make that area as place-specific advantage and to enforce its attractiveness and then advertising them as place product for marketing. 


\section{The schematic research approach}

- $\quad$ Selecting "geographically-defined area," usually a place or a city.

- Identifying and evaluating "problematic issues" of the target city - how significant these issues are in influencing bad images on the city.

- Doing geographical "place audit" in the problem area of the city so as to find out major reasons which brings about bad image to the city and spiraling down of city function.

- Making "place asset" so as to utilize it in rebuilding city image and place promotion.

- Developing conceptual model of "city identity establishment" as shown in the Figure 1.

Figure 1: The concept of research framework

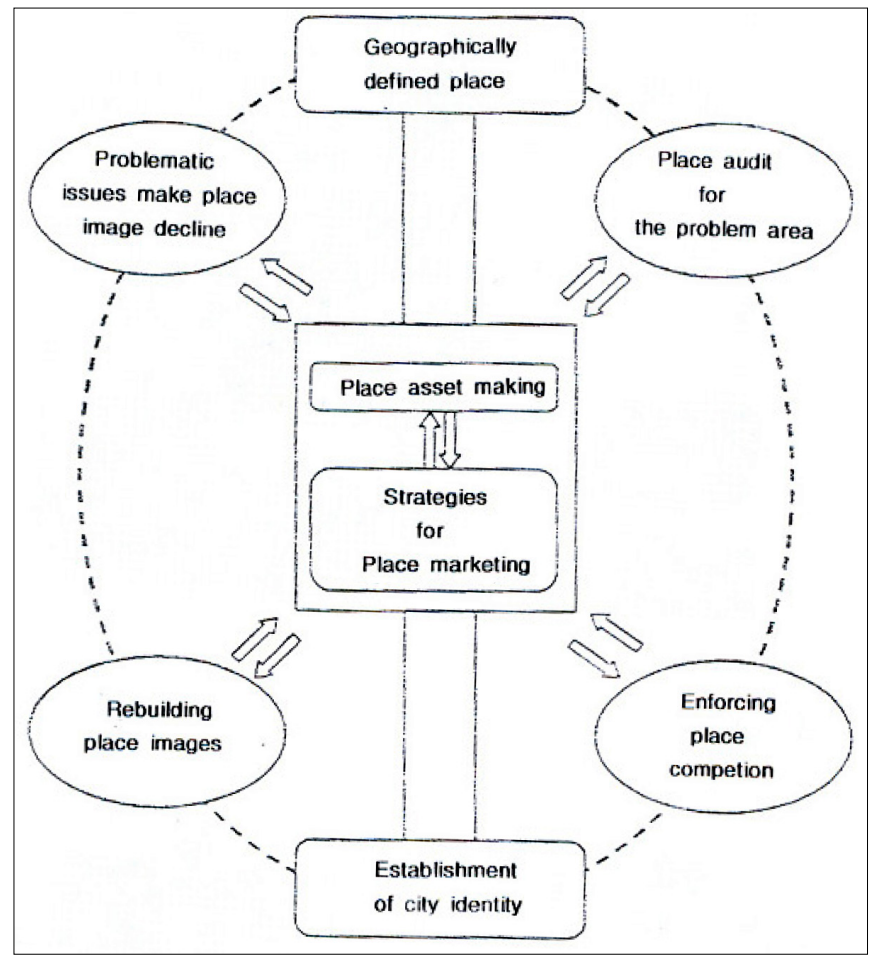

\section{KIMPO - THE CITY IMAGE IN DECLINE}

\section{The fast growing suburban city}

Kimpo is a small-medium size city with inhabitant of about 200,000 and located immediately near Seoul to the northwest in Seoul metropolitan region. Geographically Kimpo is a land of small peninsula which parallels to Han River toward the river mouth. Kimpo is approximately in the middle of the Seoul metropolitan region and a typical suburb of Seoul. 
Near Kimpo city, there are domestic Kimpo Airport and Incheon International Airport. Kimpo is a dynamically growing city with respect to its influx of population, car increase, and an expansion of urban infrastructures. For this, Kimpo seems to have a very high potentiality in city development in the near future. But, on the other hand, the fast tempo of the urban growth and change would likely to deteriorate Kimpo's city life in the many fields, for example, in housing, in transportation, in education, etc. And the deteriorations make city image even bad.

\section{Transportation problem - the main factor to Kimpo's city image decline}

If we examine some current problematic urban issues in the context of "place audit" we can understand what makes Kimpo a negative city. The most critical one, among the many issues, is the difficulty of transportation in intra and interurban movement. The heavy traffic flows and high traffic congestion are very serious problem providing inconveniences in everyday city life to Kimpo citizens. Particularly, the main artery national road, No. 48, passing through Kimpo city and connecting Seoul is the number one road in the stagnation of car travelling in the nation (See Fig.2).

Figure 2: National road, No.48: heavy traffic flows \& congestion
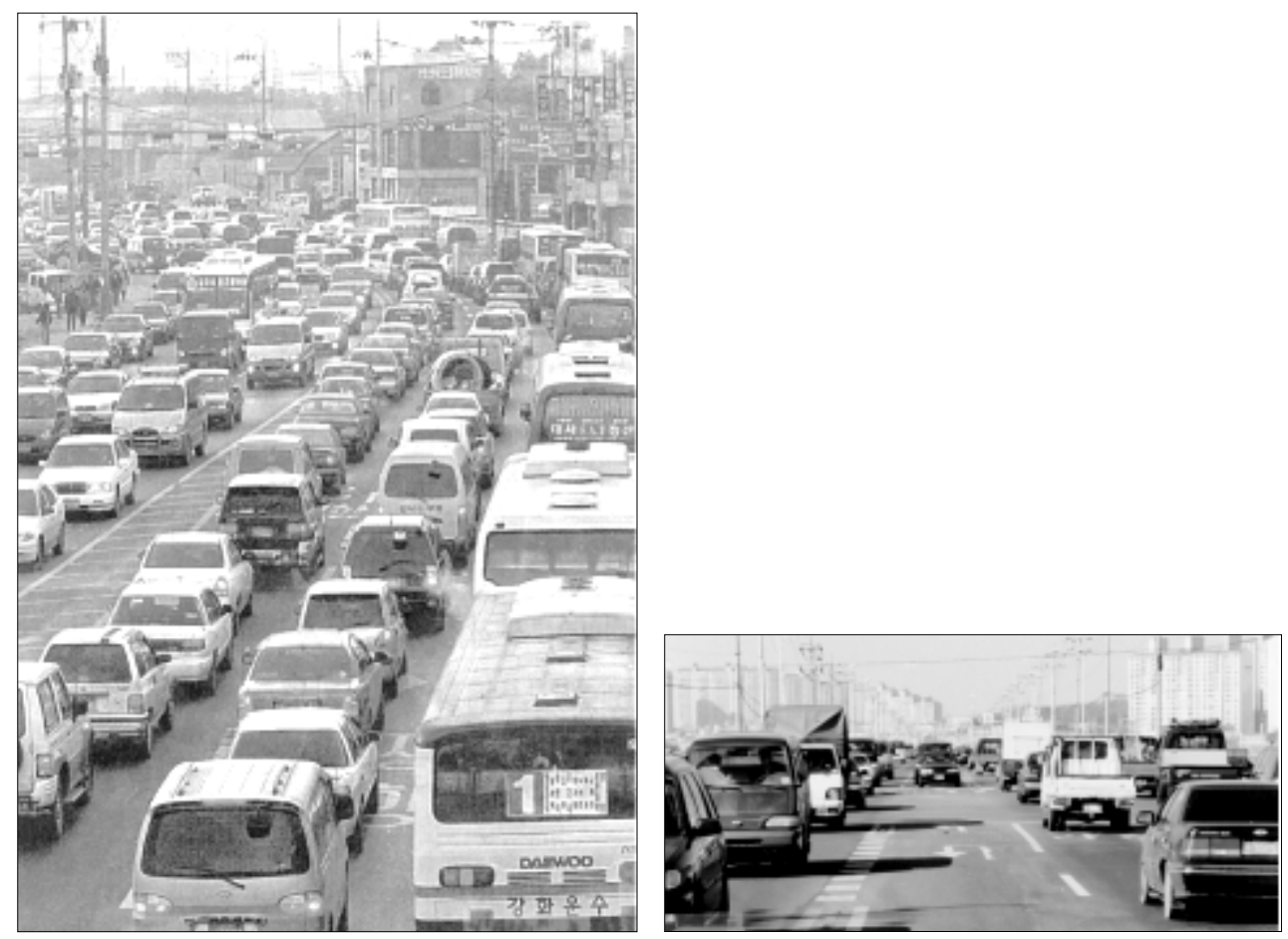
The traffic problem of No. 48 is especially related to the structure of Kimpo's road-network system. The network system is very similar to the system of river channel, which composes one main river stream to be linked with the other secondary river streams. So, the main artery is always busy by the unusual traffic volumes. Another factor which causes traffic flows heavy in Kimpo is seriously related to the more than three thousands small-medium sized factories which are scattered around in Kimpo city(See Fig.3). The wayward location and distribution of factories is also the significant factor which causes heavy car flows on the Kimpo roads, specially during the morning rush hours the moving cars on the main artery No.48 from Seoul to Kimpo direction are mainly those cars heading for factories. Therefore, during the rush hours No.48 is always jammed both ways.

For all these, ordinary people have bad image against Kimpo city and they even feel that Kimpo is a less favorable place to live in.

Figure 3: Small size factories scattered around Kimpo City

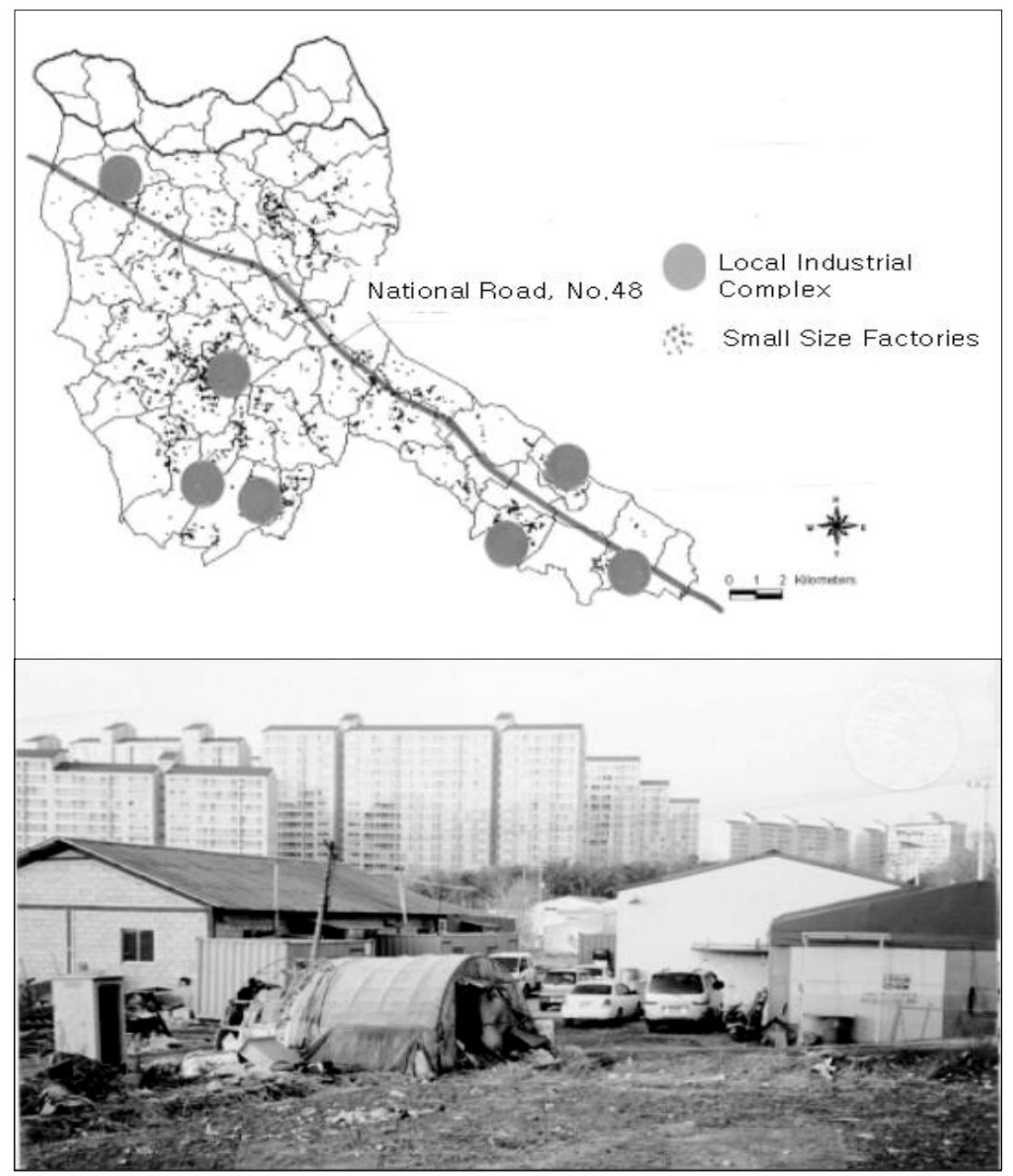




\section{PLANS FOR PLACE PROMOTION AND CITY MARKETING}

This section discusses an idea for improving the transportation problem in Kimpo City and innovating the existing bus lines in Kimpo's road network, and particularly the one on the national road, No. 48. The idea composes three different component systems (See Fig. 4) and the discussions are relevant to the notion of place asset making and place marketing strategy.

Bus Rapid Transit (BRT) System - The system, called the "surface subway", is operated by three facilities, the express bus, the tube station, and the exclusive traffic center lane. The exclusive lane enables a considerably higher average bus speed without jeopardizing passenger safety. The tube station enables passenger level boarding and exit and bus fare charged beforehand. Thus, the function of tube station is exactly same with that of subway station's platform. The express bus is larger than the ordinary bus. The bus unit has a capacity for more than 200 passengers. The express bus operates only along exclusive lanes.

BRT system, because of its efficiency and capacity, might substitute the role up to now reserved for the "pre-subway" or light railway system. The BRT system indeed will perform a revolutionary solution for linking Kimpo to Seoul through the No. 48 national road.

BRT Transfer Terminal System - Arriving at any of the BRT terminals, the passenger may change to another bus, continuing the trip, without paying any extra fare. The terminal includes two bus-bays, one for using tube station, the other for using the ordinary bus stop. There is also a taxi stop side by side with ordinary bus stop in the same bus-bay. The center lane is used only for the express buses and the outer lanes are those for slower traffic buses and other travelling vehicles.

Integration System of Different Bus Lines - the BRT system integrates all the existing bus lines at BRT terminal in Kimpo City.

- The express bus route: red buses are used and they connect all the transfer terminals on the express route. And the pre-paid access with floor loading and unloading is by means of the tube stations along the express route.

- The inter district bus route: it operates by using the conventional orange buses, with a capacity of 60 passengers. They link the main districts in the city and also connect the other municipalities.

- The local feeder route: it operates by using green mini-buses, with a capacity for 30 passengers. The mini-buses circle the surrounding neighborhoods and stop in the BRT terminal at the ordinary bus stop. Also, there are many mini-bus stops on the circle line, and one big size parking lot, called "park and ride" on the circle line for the pri-vate car users. 
Figure 4: Bus rapid transit system

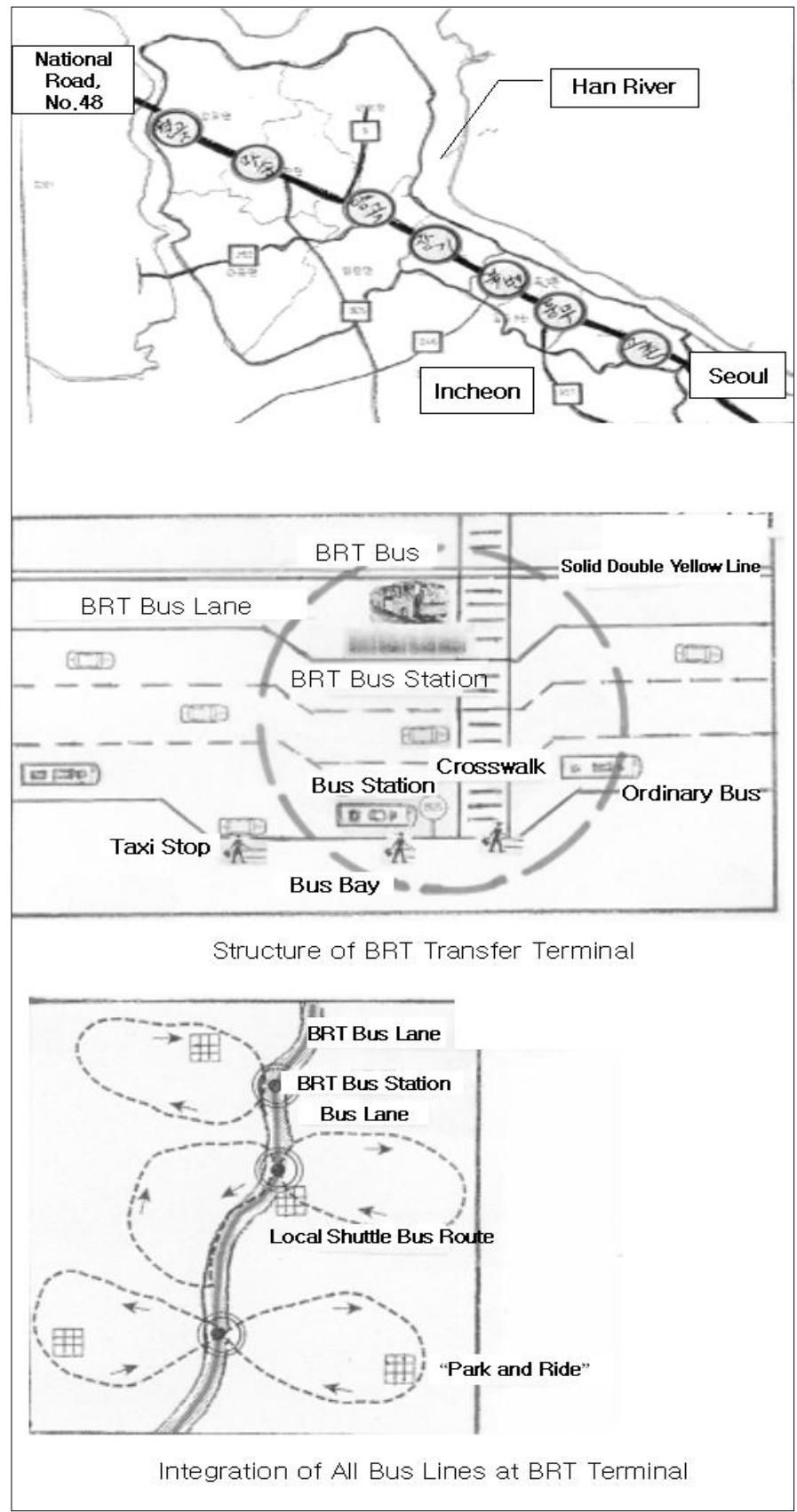




\section{CONCLUDING REMARKS: STUDY EFFECTS}

The successful operation of BRT system would bring many advantageous effects:

- $\quad$ increasing average vehicle speed on the main road, No. 48 and reducing average travel times,

- expansion of using for public transportation system and reducing private car uses,

- connection from Kimpo downtown to Seoul, actually to Kimpo Airport subway station within 20 minutes during the rush hour via BRT express bus route.

The BRT system will become a new brand as Kimpo's place asset, and also as city advertising resource. Indeed, the BRT would be the place product which is made first by Kimpo City in the nation. And Kimpo will have a good chance to overcome the bad image known as "an unfavorable place to live in" by transportation problem.

Finally, the idea of BRT system, which I have developed, will be accepted by Kimpo City government. The Kimpo authority has planned programs to introduce the BRT system operation. The plan is soon on implementation stage.

\section{Refernces}

Dowling, R. 1997: "Planning for Culture in Urban Australia", Australian Geographica Studies 35(1), pp.23-45.

Gold, J.R. \& S.V.Ward (eds.), 1994: Place Promotion: The Use of Publicity and Marketing to Sell Towns and Regions, New York: John Wiley \& Sons.

Gomez, Maaria, 1997: "Reflective images: the Case of Urban Regeneration in Glasgow and Bilbao", International Journal of Urban \& Regional Research, 22(1).

Kearns, G. and C. Philo (eds.), 1993: Selling Places: The City as Cultural Capital, Past and Present, Oxford: Pergamon Press.

Kye, Ki-Seok \& Hyeon-Sook Chun, 2001: Strategies to Establish City Identity in an Era of Decentralization, Korea Research Institute for Human Settlements.

Kim, Hyieon-Ho, 2003: "Place asset making in Place Marketing for Regional Development," 36(3), pp.77-95.

Ronan Paddison, 1993: "City Marketing, Image Reconstruction and Urban Regeneration," Urban Studies, 30(2), pp.339-50. 